radical trachelectomy for fertility-sparing treatment in women affected by cervical cancer (stage 1B-IIA1). Gynecol Oncol 122(3): 484-490

Morice P, Castaigne D, Pautier P, Rey A, Haie-Meder C, Leblanc M, Duvillard P (1999) Interest of pelvic and paraaortic lymphadenectomy in patients with stage IB and II cervical carcinoma. Gynecol Oncol 73(1): $106-110$
Sevin BU, Nadji M, Lampe B, Lu Y, Hilsenbeck S, Koechli OR, Averette HE (1995) Prognostic factors of early stage cervical cancer treated by radical hysterectomy. Cancer 76(10 suppl): 1978-1986.

Signorelli M, Guerra L, Montanelli L, Crivellaro C, Buda A, Dell'Anna T, Picchio M, Milani R, Fruscio R, Messa C (2011) Preoperative staging of cervical cancer: is 18-FDG-PET/CT really effective in patients with early stage disease? Gynecol Oncol 123(2): 236-240.

*Correspondence: Dr A Buda; E-mail: alebuda1972@mail.com

Published online 14 August 2014

(c) 2014 Cancer Research UK. All rights reserved 0007-0920/14

\section{(c) (i) (2) (2)}

http://creativecommons.org/licenses/by-nc-sa/3.0/

\title{
Response to comment on 'Preoperative nomogram for the identification of lymph node metastasis in early cervical cancer'
}

J-H Nam ${ }^{*}, 1$, D-Y Kim ${ }^{1}$ and S-H Shim ${ }^{2}$

${ }^{1}$ Department of Obstetrics and Gynecology, University of Ulsan College of Medicine, Asan Medical Center, Seoul, Korea and ${ }^{2}$ Department of Obstetrics and Gynecology, Konkuk University School of Medicine, Seoul, Korea

Sir,

We would like to thank Buda et al, 2014 for their valuable comments on our study. They make three comments. First, is there really a commitment to offer lymphadenectomy to all women with early-stage cervical cancer? Second, is there an algorithm or nomogram to assess the nodal risk involvement to better select women who can really benefit from retroperitoneal surgical staging? Finally, what is the impact of those tools in the decision making in women desiring to preserve fertility?

So far, pelvic lymphadenectomy is endorsed as a standard surgical procedure in early-stage cervical cancer including stage IA1 disease with lymphovascular space invasion (Koh et al, 2013). However, $\sim 80 \%$ of earlylymphadenectomy in these patients is still controversial. Some authors suggested that among node-negative patients survival is improved when a greater number of lymph nodes are removed because of better extraction of micrometastasis (Shah et al, 2011). Therefore, lymphadenectomy in earlystage cervical cancer should be offered until clinical trials elucidate the therapeutic value of lymphadenectomy in node-negative disease. results of our study show accurate identification of the low-risk group of LNM and we believe it could help patients' stratification in designing such trials. Although our nomogram is dependent on the status of lymph node detected by PET/CT, the other two factors (age and tumour size) are incorporated into the model to compensate the false-negative findings of PET/CT. As Buda et al, 2014 commented, PET/CT sensitivity and negative predictive values seem to be low in the early-stage cervical cancer patients with tumour size $<4 \mathrm{~cm}$ (Signorelli et al, 2011), although PET/CT is the most accurate imaging tool for assessment of nodal status in cervical cancer currently. After review of our data set comprising a model development cohort with tumour size $<4 \mathrm{~cm}$ $(n=248)$, PET/CT sensitivity and negative predictive values were $63.9 \%$ and $93.5 \%$, respectively. We believe the main reason for the difference in this subgroup could be the different proportions of micrometastasis (defined as metastatic deposits $<5 \mathrm{~mm}$ ). Of the 36 cervical cancer node-positive patients, $14(39 \%)$ patients showed micrometastases in our data set, whereas $56 \%$ nodepositive patients $(34 / 61)$ demonstrated micrometastases in previous series of Buda et al, 2014 We agree with Buda's opinion that metabolic tumour volume (MTV) correlates with lymph node metastasis. In our recent study of 84 endometrial cancer patients, the group with MTV $\geq 17.15 \mathrm{ml}$ was significantly associated with lymph node metastasis (Shim et al, 2014). Using this volumetric functional parameter or combining sentinel lymph node (SLN) biopsy could lead to improvement in our model.

To confer the benefits of SLN biopsy to patients who desire to preserve fertility, a careful preoperative evaluation for eligible patients is important. Although SLN biopsy may be useful for avoiding complete lymphadenectomy, its routine clinical use is still limited because of technical difficulties and prerequisites such as a nuclear medicine department, intraoperative frozen sections, and ultrastaging. In addition, SLN detection rate was reported to be associated with tumour size and preoperative conisation; SLN detection rate was statistically lower in patients with tumour sizes $>3 \mathrm{~cm}$ (Du et al, 2011) and those with conisation (Dargent and Enria, 2003; Seong stage cervical cancer patients are node-negative and the therapeutic effect of

It is clear that patient selection for such trials is the critical issue. The

et al, 2007). Thus, SLN biopsy would be useful for detecting nodal metastasis in small-volume tumour, and using imaging modalities such as PET/CT would be useful in other cases. In this regard, the nomogram conjuncted with SLN biopsy would be clinically helpful for selecting appropriate patients who wish to preserve fertility and could be treated with radical trachelectomy.

As suggested by Buda et al, 2014, we think that SLN biopsy is of great value in early cervical cancer patients, especially in those with small-size tumor. However, its clinical use is still limited because of technical difficulties and lack of standardisation. Our developed nomogram is a non-invasive, easily applicable, and user-friendly tool. We believe that the nomogram will allow selection of a patient population at low risk for nodal metastasis and thus facilitate the design of clinical trials. Definitely, as suggested by Buda et al, 2014, assessment of nodal status solely by PET/CT still represents a challenge and the nomogram requires rigorous validation. Thus, future researches should focus on testing whether the predictive performance can be shown in other independent cohorts and enhanced by incorporating SLN biopsy.

\section{CONFLICT OF INTEREST}

The authors declare no conflict of interest.

\section{REFERENCES}

Buda A, Guerra L, Crivellaro C (2014) Comment on 'Pre-operative nomogram for the identification of lymph node metastasis in early cervical cancer'. Br J Cancer 111(12): 2370-2371.

Dargent D, Enria R (2003) Laparoscopic assessment of the sentinel lymph nodes in early cervical cancer. Technique-preliminary results and future developments. Crit Rev Oncol/Hematol 48: 305-310.

Du XL, Sheng XG, Jiang T, Li QS, Yu H, Pan CX, Lu CH, Wang C, Song QQ (2011) Sentinel lymph node biopsy as guidance for radical trachelectomy in young patients with early stage cervical cancer. BMC Cancer 11: 157

Koh WJ, Greer BE, Abu-Rustum NR, Apte SM, Campos SM, Chan J, Cho KR, Cohn D, Crispens MA, DuPont N, Eifel PJ, Gaffney DK, Giuntoli 2nd RL, Han E, Huh WK, Lurain 3rd JR, Martin L, Morgan MA, Mutch D, Remmenga SW, Reynolds RK, Small Jr W, Teng N, Tillmanns T, Valea FA, McMillian NR, Hughes M (2013) Cervical cancer. J Natl Compr Canc Netw 11: 320-343.

Seong SJ, Park H, Yang KM, Kim TJ, Lim KT, Shim JU, Park CT, Lee KH (2007) Detection of sentinel lymph nodes in patients with early stage cervical cancer. I Korean Med Sci 22: 105-109.

Shah M, Lewin SN, Deutsch I, Burke WM, Sun X, Herzog TJ, Wright JD (2011) Therapeutic role of lymphadenectomy for cervical cancer. Cancer 117: 310-317.

Shim SH, Kim DY, Lee DY, Lee SW, Park JY, Lee J, Kim JH, Kim YM, Kim YT, Nam JH (2014) Metabolic tumour volume and total lesion glycolysis, measured using preoperative F-FDG PET/CT, predict the recurrence of endometrial cancer. BJOG; e-pub ahead of print 8 January 2014; doi:10.1111/14710528.12543 .

Signorelli M, Guerra L, Montanelli L, Crivellaro C, Buda A, Dell'Anna T, Picchio M, Milani R, Fruscio R, Messa C (2011) Preoperative staging of cervical cancer is 18-FDG-PET/CT really effective in patients with early stage disease? Gynecol Oncol 123: 236-240.

*Correspondence: Professor J-H Nam; E-mail: jhnam@amc.seoul.kr Published online 14 August 2014

(c) 2014 Cancer Research UK. All rights reserved 0007 - 0920/14

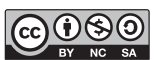

http://creativecommons.org/licenses/by-nc-sa/3.0/ 